\title{
On orthogonal resolutions of the classical Steiner quadruple system SQS(16)
}

\author{
Hans Ludwig de Vries
}

Received: 22 February 2008 / Revised: 20 March 2008 / Accepted: 25 March 2008 /

Published online: 16 April 2008

(C) The Author(s) 2008

\begin{abstract}
A Steiner quadruple system $\operatorname{SQS}(16)$ is a pair $(V, \mathcal{B})$ where $V$ is a 16-set of objects and $\mathcal{B}$ is a collection of 4-subsets of $V$, called blocks, so that every 3 -subset of $V$ is contained in exactly one block. By classical is meant the boolean quadruple system, also known as the affine geometry AG(4,2). A parallel class is a collection of four blocks which partition $V$. The system possesses a resolution or parallelism, since $\mathcal{B}$ can be partitioned into 35 parallel classes. Two resolutions are called orthogonal when each parallel class of one resolution has at most one block in common with each parallel class of the other resolution. We prove that there are at most nine further resolutions which, together with the classical one, are pairwise orthogonal.
\end{abstract}

Keywords Steiner quadruple system $\cdot$ Automorphism group $\cdot$ Resolutions

AMS Classifications $\quad 05 \mathrm{~B} 05 \cdot 05 \mathrm{~B} 07 \cdot 51 \mathrm{E} 10$

\section{The automorphism group $M$ of the SQS(16)}

The Reverend T. P. Kirkman knew in 1862 that there exists a group of degree 16 and order 322560 with a normal, elementary abelian, subgroup of order 16 [1, p. 108]. Frobenius identified this group in 1904 as a subgroup of the Mathieu group $M_{24}$ [4, p. 570]:

$\mathfrak{M}_{16}$ ist die dreifach transitive lineare Gruppe der Ordnung

$$
2^{4}\left(2^{4}-1\right)\left(2^{4}-2\right)\left(2^{4}-2^{2}\right)\left(2^{4}-2^{3}\right) .
$$

Communicated by J. D. Key.

H. L. de Vries $(\varangle)$

Institut für Numerische und Angewandte Mathematik, Georg-August-Universität Göttingen,

Lotzestraße 16-18, 37083 Göttingen, Germany

e-mail: devries@math.uni-goettingen.de 
Sie enthält die elementare Gruppe $\mathfrak{R}$ der Ordnung 16 als invariante Untergruppe, und $\frac{\mathfrak{M}_{16}}{\mathfrak{R}}=\mathfrak{T}_{8}$ ist der alternierenden Gruppe des Grades 8 isomorph.

In the ATLAS [3, p. 96] the group is noted as maximal subgroup of $M_{24}$ with structure $2^{4}: A_{8}$. We call this group $M$ with $N$ its normal subgroup and generate $M:=\langle\alpha, \gamma\rangle$ by

$$
\alpha:=(12498 \mathrm{AE7F} 5 \mathrm{BC} 36 \mathrm{D}), \quad \gamma:=(08)(1 \mathrm{E} 2 \mathrm{~B} 5 \mathrm{~F} 496 \mathrm{~A} 3 \mathrm{D} 7 \mathrm{C}) .
$$

Then $N$ consists of the identity and a conjugacy class of size 15 ,

$$
N=(1) \cup\left\{\alpha^{-i} \gamma^{7} \alpha^{i} \mid i=1, \ldots, F\right\} .
$$

\section{The SQS(16) and the orbits $\mathcal{O}_{i}$ of parallel classes}

In 1980 Hartman [5] has given some sets of mutually orthogonal resolutions of quadruple systems, using groups $\operatorname{PSL}(2, q)$. Hartman and Phelps [6] have raised the general resolvability question for SQS and stated: 'There is no good upper bound on the number of mutually orthogonal resolutions of an SQS (p. 226) ..... We treat the special case of the SQS(16) where

$$
V:=0123456789 \mathrm{ABCDEF}, \quad \mathcal{B}:=\{g B \mid g \in M\}
$$

with block $B:=0123$.

To form resolutions we need the set of parallel classes. A backtrack search reveals that its cardinality is $1505=43 \times 35$. The group $M$ partitions it into orbits $\mathcal{O}_{1}, \mathcal{O}_{2}$ and $\mathcal{O}_{3}$ of lengths $35,18 \times 35$ and $24 \times 35$. Orbit $\mathcal{O}_{1}$ is the SQS(16) which is listed explicitly in Appen$\operatorname{dix} \mathcal{O}_{1}$. The group $M$ generates the orbits $\mathcal{O}_{i}=\left\{g \mathcal{P}_{i} \mid g \in M\right\}$ where the parallel classes are

\begin{tabular}{lllllllll}
\hline \multicolumn{3}{c}{ Block numbers } & \multicolumn{7}{c}{ Parallel classes } \\
\hline $\mathcal{P}_{1}$ & 1 & 102 & 127 & 140 & 0123 & 4567 & $89 \mathrm{AB}$ & $\mathrm{CDEF}$ \\
$\mathcal{P}_{2}$ & 1 & 102 & 128 & 139 & 0123 & 4567 & $89 \mathrm{CD}$ & $\mathrm{ABEF}$ \\
$\mathcal{P}_{3}$ & 1 & 103 & 125 & 139 & 0123 & 4589 & $67 \mathrm{CD}$ & $\mathrm{ABEF}$ \\
\hline
\end{tabular}

The four blocks of every parallel class $\mathcal{P} \in \mathcal{O}_{2}$ lie in two parallel classes of $\mathcal{O}_{1}$ : No resolution in $\mathcal{O}_{2}$ is orthogonal to $\mathcal{O}_{1}$.

The four blocks of every parallel class $\mathcal{P} \in \mathcal{O}_{3}$ lie in four parallel classes of $\mathcal{O}_{1}$ : Every resolution in $\mathcal{O}_{3}$ is orthogonal to $\mathcal{O}_{1}$.

\section{The normal subgroup $N$ and its subgroups}

The non-identity elements of $N$ consist of eight 2-cycles $(i, j), 0 \leq i<j \leq F$, which we call $\delta_{j}$ if the first 2-cycle is $(0, j)$. Altogether their number is $15 \times 8=\left(\begin{array}{c}16 \\ 2\end{array}\right)$. They are listed in Appendix $N$. They describe a 'proper edge coloring' of the complete graph $K_{16}$.

The group $N$ and its subgroups lead to a Steiner triple system and its subsystems. A Steiner triple system $\operatorname{STS}(v)$ is a collection of blocks of size 3 taken from a $v$-set of objects such that every two objects belong to precisely one block. Since $N$ is the direct product of four groups of order 2 we create an STS(15) by taking as objects the 15 permutations $\delta_{i} \in N$ and as blocks the triples $\left\{\delta_{i}, \delta_{j}, \delta_{i} \delta_{j}\right\}$. It is isomorphic to the derivation of the SQS(16) of 
Appendix $\mathcal{O}_{1}$ : Take there the first 35 blocks, delete the object 0, and an STS(15) is left over. Its objects $i$ are the $\delta_{i}$ here. The systems are isomorphic to the STS(15) of [7, p. 17] and [2, p. $65 \# 1$ ].

The automorphism group of the STS(15) is the $P S L(4,2)$ of order 20160. It is generated by

$$
\alpha:=(12498 \mathrm{AE7F} 5 \mathrm{BC} 36 \mathrm{D}), \quad \beta:=(1254637)(9 \mathrm{ADCEBF}),
$$

taken over from [7, p. 17]. The permutation $\beta$ has in $M$ the unique square root $\gamma, \gamma^{2}=\beta$. It is the reason we generate $M$ by $\alpha$ and $\gamma$. Uniqueness of $\gamma$ follows from the observation that in $M$ the four conjugacy classes with representatives $\beta, \beta^{-1}$ of order 7 and $\gamma, \gamma^{-1}$ of order 14 have the same size 23040.

\section{Partitioning $\mathcal{O}_{3}$ into 15 tiles $\mathcal{T}_{i}$}

Let $N$ act on each parallel class $\mathcal{P} \in \mathcal{O}_{3}$ : The stabilizers $\operatorname{Stab}_{N}(\mathcal{P})$ are of order 2, so every $\mathcal{P} \in \mathcal{O}_{3}$ is fixed by a unique $\delta_{i} \in N$. They partition $\mathcal{O}_{3}$ into 15 sets of parallel classes which we call tiles $\mathcal{T}_{i}$,

$$
\mathcal{T}_{i}:=\left\{\mathcal{P} \in \mathcal{O}_{3} \mid \delta_{i} \mathcal{P}=\mathcal{P}\right\} .
$$

The tiles are of cardinality $(24 \times 35) / 15=56$, involved are 28 blocks of multiplicity 8 . The permutation $\alpha \in M$ of order 15 permutes the tiles. Incidentally, the 140 blocks $B \in \mathcal{B}$ have stabilizers $\operatorname{Stab}_{N}(B)$ of order 4 . In the following proposition we use the definition of orthogonal resolutions [6, pp. 225-226] also for pairs of sets of parallel classes.

\section{Two propositions and the theorem}

Proposition 1 The 15 tiles $\mathcal{T}_{i}$ are pairwise orthogonal.

Proof If a parallel class $\mathcal{P}$ is sent to $\mathcal{T}_{i}$, it takes with it all the $\left(\begin{array}{l}4 \\ 2\end{array}\right)=6$ parallel classes which have two blocks with $\mathcal{P}$ in common. For example, as the parallel class $\mathcal{P}_{3} \in \mathcal{O}_{3}$ goes to $\mathcal{T}_{1}$, so do the six others:

\begin{tabular}{rrrrrrrl}
\hline 1 & 103 & 125 & 139 & 0123 & 4589 & $67 \mathrm{CD}$ & $\mathrm{ABEF}$ \\
\hline 1 & 103 & 126 & 138 & 0123 & 4589 & $67 \mathrm{EF}$ & $\mathrm{ABCD}$ \\
1 & 104 & 125 & 129 & 0123 & $45 \mathrm{AB}$ & $67 \mathrm{CD}$ & $89 \mathrm{EF}$ \\
1 & 105 & 123 & 139 & 0123 & $45 \mathrm{CD}$ & 6789 & $\mathrm{ABEF}$ \\
7 & 67 & 103 & 125 & $01 \mathrm{EF}$ & $23 \mathrm{AB}$ & 4589 & $67 \mathrm{CD}$ \\
3 & 68 & 103 & 139 & 0167 & $23 \mathrm{CD}$ & 4589 & $\mathrm{ABEF}$ \\
4 & 64 & 125 & 139 & 0189 & 2345 & $67 \mathrm{CD}$ & $\mathrm{ABEF}$ \\
\hline
\end{tabular}

The reason: Pairs of $\delta_{1}=(01)(23)(45)(67)(89)(\mathrm{AB})(\mathrm{CD})(\mathrm{EF})$ are pairs in the blocks.

This set of seven parallel classes can be called a 'sphere', the first one being its 'centre'. A tile can in 105 ways be covered with a perfect 'sphere packing' of eight spheres, $8 \times 7=56$.

Proposition 2 In every tile the maximal number of its 56 parallel classes which have pairwise at most one block in common is equal to 21.

Proof By backtrack searches. In a tile there are eight such 21-sets. They consist of all the 28 blocks of its tile, each block appearing three times. 
From the two propositions follows the result of this paper:

Theorem The classical SQS(16) has at most 9 more resolutions such that they are pairwise orthogonal.

Proof

$$
15 \times 21=9 \times 35 .
$$

\section{A lower bound}

Here is an example of six pairwise orthogonal resolutions in $\mathcal{O}_{3}$. Provided $\mathcal{O}_{3}$ is sorted we represent its parallel classes by positional parameters. The 24 letters $a, \ldots, x$ stand for the numbers $1, \ldots, 24$. A letter $z$ at position $s, 1 \leq s \leq 35$, refers to the parallel class $\mathcal{P}_{j}$ where $j=(s-1) \times 24+z$. A first resolution is

amgtxdumchdunuqmeqhebqkhpxxmnbiwdto.

To produce four more let the group $\left\langle\alpha^{3}\right\rangle$ act on it. Their automorphism groups are the identity. The sixth resolution with automorphism group $\left\langle\alpha^{3}\right\rangle$ is

\section{jbjumtiuxeaxkptluidlgjmfbqidfdtqumv.}

Earlier Hartman [5, p. 162] has given a set of seven mutually orthogonal resolutions of an $\operatorname{SQS}(q+1)$ for $q=43$.

\section{Orbit $\mathcal{O}_{2}$}

Every parallel class $\mathcal{P} \in \mathcal{O}_{2}$ has a stabilizer $\operatorname{Stab}_{N}(\mathcal{P})$ of order 8 . For the $\mathcal{P}_{2} \in \mathcal{O}_{2}$ it is the subgroup $N^{\prime}$ of $N$,

$$
N^{\prime}:=(1) \cup\left\{\delta_{i} \in N \mid i=1, \ldots, 7\right\} .
$$

There are 15 stabilizers, the conjugacy class $\left\{\alpha^{-i} N^{\prime} \alpha^{i} \mid i=1, \ldots, F\right\}$. They partition $\mathcal{O}_{2}$ into 15 sets of cardinality $(18 \times 35) / 15=42$ which are not pairwise orthogonal. The stabilizers lead to the 15 subsystems (Fano planes) STS(7) of the STS(15) [7, p. 17].

Acknowledgments The author thanks Eberhard Schmitt for helpful discussions and the Institut für Numerische und Angewandte Mathematik at Göttingen for generous hospitality.

Open Access This article is distributed under the terms of the Creative Commons Attribution Noncommercial License which permits any noncommercial use, distribution, and reproduction in any medium, provided the original author(s) and source are credited.

\section{Appendices}

Appendix $N$ The normal subgroup $N$, elements $\neq(1)$

$$
\begin{aligned}
& \delta_{1}:=(01)(23)(45)(67)(89)(\mathrm{AB})(\mathrm{CD})(\mathrm{EF}) \\
& \delta_{2}:=(02)(13)(46)(57)(8 \mathrm{~A})(9 \mathrm{~B})(\mathrm{CE})(\mathrm{DF})
\end{aligned}
$$




$$
\begin{aligned}
& \delta_{3}:=(03)(12)(47)(56)(8 \mathrm{~B})(9 \mathrm{~A})(\mathrm{CF})(\mathrm{DE}) \\
& \delta_{4}:=(04)(15)(26)(37)(8 \mathrm{C})(9 \mathrm{D})(\mathrm{AE})(\mathrm{BF}) \\
& \delta_{5}:=(05)(14)(27)(36)(8 \mathrm{D})(9 \mathrm{C})(\mathrm{AF})(\mathrm{BE}) \\
& \delta_{6}:=(06)(17)(24)(35)(8 \mathrm{E})(9 \mathrm{~F})(\mathrm{AC})(\mathrm{BD}) \\
& \delta_{7}:=(07)(16)(25)(34)(8 \mathrm{~F})(9 \mathrm{E})(\mathrm{AD})(\mathrm{BC}) \\
& \delta_{8}:=(08)(19)(2 \mathrm{~A})(3 \mathrm{~B})(4 \mathrm{C})(5 \mathrm{D})(6 \mathrm{E})(7 \mathrm{~F}) \\
& \delta_{9}:=(09)(18)(2 \mathrm{~B})(3 \mathrm{~A})(4 \mathrm{D})(5 \mathrm{C})(6 \mathrm{~F})(7 \mathrm{E}) \\
& \delta_{A}:=(0 \mathrm{~A})(1 \mathrm{~B})(28)(39)(4 \mathrm{E})(5 \mathrm{~F})(6 \mathrm{C})(7 \mathrm{D}) \\
& \delta_{B}:=(0 \mathrm{~B})(1 \mathrm{~A})(29)(38)(4 \mathrm{~F})(5 \mathrm{E})(6 \mathrm{D})(7 \mathrm{C}) \\
& \delta_{C}:=(0 \mathrm{C})(1 \mathrm{D})(2 \mathrm{E})(3 \mathrm{~F})(48)(59)(6 \mathrm{~A})(7 \mathrm{~B}) \\
& \delta_{D}:=(0 \mathrm{D})(1 \mathrm{C})(2 \mathrm{~F})(3 \mathrm{E})(49)(58)(6 \mathrm{~B})(7 \mathrm{~A}) \\
& \delta_{E}:=(0 \mathrm{E})(1 \mathrm{~F})(2 \mathrm{C})(3 \mathrm{D})(4 \mathrm{~A})(5 \mathrm{~B})(68)(79) \\
& \delta_{F}:=(0 \mathrm{~F})(1 \mathrm{E})(2 \mathrm{D})(3 \mathrm{C})(4 \mathrm{~B})(5 \mathrm{~A})(69)(78)
\end{aligned}
$$

\section{Appendix $\mathcal{O}_{1}$ The SQS(16)}

\begin{tabular}{rrrrllll}
\hline \multicolumn{7}{l}{ Block numbers } & \multicolumn{7}{l}{ Parallel classes } \\
\hline 1 & 102 & 127 & 140 & 0123 & 4567 & $89 \mathrm{AB}$ & $\mathrm{CDEF}$ \\
2 & 65 & 128 & 139 & 0145 & 2367 & $89 \mathrm{CD}$ & $\mathrm{ABEF}$ \\
3 & 64 & 129 & 138 & 0167 & 2345 & $89 \mathrm{EF}$ & $\mathrm{ABCD}$ \\
4 & 67 & 105 & 126 & 0189 & $23 \mathrm{AB}$ & $45 \mathrm{CD}$ & $67 \mathrm{EF}$ \\
5 & 66 & 106 & 125 & $01 \mathrm{AB}$ & 2389 & $45 \mathrm{EF}$ & $67 \mathrm{CD}$ \\
6 & 69 & 103 & 124 & $01 \mathrm{CD}$ & $23 \mathrm{EF}$ & 4589 & $67 \mathrm{AB}$ \\
7 & 68 & 104 & 123 & $01 \mathrm{EF}$ & $23 \mathrm{CD}$ & $45 \mathrm{AB}$ & 6789 \\
8 & 43 & 130 & 137 & 0246 & 1357 & $8 \mathrm{ACE}$ & $9 \mathrm{BDF}$ \\
9 & 42 & 131 & 136 & 0257 & 1346 & $8 \mathrm{ADF}$ & $9 \mathrm{BCE}$ \\
10 & 45 & 109 & 122 & $028 \mathrm{~A}$ & $139 \mathrm{~B}$ & $46 \mathrm{CE}$ & $57 \mathrm{DF}$ \\
11 & 44 & 110 & 121 & $029 \mathrm{~B}$ & $138 \mathrm{~A}$ & $46 \mathrm{DF}$ & $57 \mathrm{CE}$ \\
12 & 47 & 107 & 120 & $02 \mathrm{CE}$ & $13 \mathrm{DF}$ & $468 \mathrm{~A}$ & $579 \mathrm{~B}$ \\
13 & 46 & 108 & 119 & $02 \mathrm{DF}$ & $13 \mathrm{CE}$ & $469 \mathrm{~B}$ & $578 \mathrm{~A}$ \\
14 & 37 & 132 & 135 & 0347 & 1256 & $8 \mathrm{BCF}$ & $9 \mathrm{ADE}$ \\
15 & 36 & 133 & 134 & 0356 & 1247 & $8 \mathrm{BDE}$ & $9 \mathrm{ACF}$ \\
16 & 39 & 113 & 118 & $038 \mathrm{~B}$ & $129 \mathrm{~A}$ & $47 \mathrm{CF}$ & $56 \mathrm{DE}$ \\
17 & 38 & 114 & 117 & $039 \mathrm{~A}$ & $128 \mathrm{~B}$ & $47 \mathrm{DE}$ & $56 \mathrm{CF}$ \\
18 & 41 & 111 & 116 & $03 \mathrm{CF}$ & $12 \mathrm{DE}$ & $478 \mathrm{~B}$ & $569 \mathrm{~A}$ \\
19 & 40 & 112 & 115 & $03 \mathrm{DE}$ & $12 \mathrm{CF}$ & $479 \mathrm{~A}$ & $568 \mathrm{~B}$ \\
20 & 53 & 80 & 101 & $048 \mathrm{C}$ & $159 \mathrm{D}$ & $26 \mathrm{AE}$ & $37 \mathrm{BF}$ \\
21 & 52 & 81 & 100 & $049 \mathrm{D}$ & $158 \mathrm{C}$ & $26 \mathrm{BF}$ & $37 \mathrm{AE}$ \\
22 & 55 & 78 & 99 & $04 \mathrm{AE}$ & $15 \mathrm{BF}$ & $268 \mathrm{C}$ & $379 \mathrm{D}$ \\
23 & 54 & 79 & 98 & $04 \mathrm{BF}$ & $15 \mathrm{AE}$ & $269 \mathrm{D}$ & $378 \mathrm{C}$ \\
24 & 49 & 84 & 97 & $058 \mathrm{D}$ & $149 \mathrm{C}$ & $27 \mathrm{AF}$ & $36 \mathrm{BE}$ \\
25 & 48 & 85 & 96 & $059 \mathrm{C}$ & $148 \mathrm{D}$ & $27 \mathrm{BE}$ & $36 \mathrm{AF}$ \\
26 & 51 & 82 & 95 & $05 \mathrm{AF}$ & $14 \mathrm{BE}$ & $278 \mathrm{D}$ & $369 \mathrm{C}$ \\
27 & 50 & 83 & 94 & $05 \mathrm{BE}$ & $14 \mathrm{AF}$ & $279 \mathrm{C}$ & $368 \mathrm{D}$ \\
28 & 61 & 72 & 93 & $068 \mathrm{E}$ & $179 \mathrm{~F}$ & $24 \mathrm{AC}$ & $35 \mathrm{BD}$ \\
29 & 60 & 73 & 92 & $069 \mathrm{~F}$ & $178 \mathrm{E}$ & $24 \mathrm{BD}$ & $35 \mathrm{AC}$ \\
30 & 63 & 70 & 91 & $06 \mathrm{AC}$ & $17 \mathrm{BD}$ & $248 \mathrm{E}$ & $359 \mathrm{~F}$ \\
31 & 62 & 71 & 90 & $06 \mathrm{BD}$ & $17 \mathrm{AC}$ & $249 \mathrm{~F}$ & $358 \mathrm{E}$ \\
32 & 57 & 76 & 89 & $078 \mathrm{~F}$ & $169 \mathrm{E}$ & $25 \mathrm{AD}$ & $34 \mathrm{BC}$ \\
33 & 56 & 77 & 88 & $079 \mathrm{E}$ & $168 \mathrm{~F}$ & $25 \mathrm{BC}$ & $34 \mathrm{AD}$ \\
34 & 59 & 74 & 87 & $07 \mathrm{AD}$ & $16 \mathrm{BC}$ & $258 \mathrm{~F}$ & $349 \mathrm{E}$ \\
35 & 58 & 75 & 86 & $07 \mathrm{BC}$ & $16 \mathrm{AD}$ & $259 \mathrm{E}$ & $348 \mathrm{~F}$ \\
\hline & & & & & & &
\end{tabular}




\section{References}

1. Biggs N.L., T. P. Kirkman.: Mathematician Bull. London Math. Soc. 13, 97-120 (1981).

2. Colbourn C.J., Rosa A.: Triple Systems. Clarendon Press, Oxford (1999).

3. Conway J.H., Curtis R.T., Norton S.P., Parker R.A., Wilson R.A.: Atlas of Finite Groups. Oxford University Press, Oxford (1985).

4. Frobenius G.: Über die Charaktere der mehrfach transitiven Gruppen. Sitzungsber. Königl. Preuss. Akad. Wiss. Berlin, 558-571 (1904). Reprinted in Serre J.-P. (ed.) Frobenius F.G., Abhandlungen G. III, pp. 335-348. Springer, Berlin (1968).

5. Hartman A.: Doubly and orthogonally resolvable quadruple systems. In: Robinson R.W., Southern G.W., Wallis W.D. (eds.) Combinatorial Mathematics VII, Lecture Notes in Mathematics, vol. 829, pp. 157-164. Springer, Berlin (1980).

6. Hartman A., Phelps K.T.: Steiner quadruple systems. In: Dinitz J.H., Stinson D.R. (eds.) Contemporary Design Theory: A Collection of Surveys, pp. 205-240. Wiley, New York (1992).

7. Mathon R.A., Phelps K.T., Rosa A.: Small Steiner triple systems and their properties. Ars Combin. 15, 3-110 (1983). 